\title{
Quantifying the risk of zoonotic geohelminth infections for rural household inhabitants in Central Poland
}

\author{
Jakub Gawor', Anna Borecka',2 \\ ${ }^{1}$ Witold Stefański Institute of Parasitology of the Polish Academy of Sciences, Warsaw, Poland \\ 2 Laboratory of Parasitology, Military Institute of Hygiene and Epidemiology, Warsaw, Poland
}

Gawor J, Borecka A.Quantifying the risk of zoonotic geohelminth infections for rural household inhabitants in Central Poland. Ann Agric Environ Med. 2017; 24(1): 44-48. doi: 10.5604/12321966.1230679

\begin{abstract}
The objective of this study was to evaluate the risk of soil transmitted zoonotic helminth infections for families with young children, inhabitants of villages in the Mazowieckie Province of Central Poland. Epidemiological survey was conducted at 33 randomly selected households with 2-3 children present. Examination of soil samples from yards surrounding the houses for the presence of geohelminth eggs was conducted, the households were inspected, and family members interviewed using a designed questionnaire. Among 55 localities examined, i.e. 33 backyards, 10 vegetable gardens and 12 sandpits, contamination was found in 2 backyards (6.1\%) and 1 sandpit (8.3\%) at 3 households (9.1\%). Of the total 550 examined soil samples, $4(0.7 \%)$ were found to contain Trichuris and Toxocara eggs, with an average density of 1.5 and 2.0 eggs per sample. The study showed a low level of soil contamination, which was the result of inhabitants care about the sanitation of their domiciles. However, the results of the questionnaire survey demonstrated the need to warn rural residents about the risk factors for zoonotic helmints infections. In particular, parents should be advised how to minimize the threat of parasitic diseases for children in the rural environment. The presented study showed that promotional campaigns implemented in recent years on the prevention of parasitic zoonoses have had little effect to increase the awareness of the rural community. The present results confirmed that Toxocara is the most common zoonotic agent among geohelminths in the rural environment.
\end{abstract}

Key words

geohelminth eggs, soil samples, contamination, rural environment

\section{INTRODUCTION}

According to the Statistical Yearbook of Agriculture (2012), in Poland there are 2.25 million farming households, of which 1.55 million $(68.9 \%)$ are small, with area up to 5 hectares. In rural areas, families with many children are more numerous than in towns. Children represent almost $17 \%$ of the rural population, while in cities less than $14 \%$.

Due to the fact that $48.8 \%$ of children in rural areas in Poland are not covered by preschool education, adequate sanitation in their household is vital to provide the children with healthy living conditions. According to numerous reports, the rural environment predisposes for the acquisition of geohelminth infections, and therefore more frequently affects the possibilities of such an acquisition due to close contact with soil, vegetation and aunwashed vegetables and fruits. Field surveys conducted in different rural settlements show a high rate of soil contamination with eggs of nematode parasites, in particular, Toxocara, Ancylostoma/Uncinaria and Trichuris $[1,2,3,4,5,6]$, some of which infect humans, while others, such as T. vulpis, Ancylostoma caninum and Uncinaria stenocephala, are potential zoonotic parasites [7, 8]. Canine and feline roundworms (T. canis and T. cati) are of the greatest epidemiological importance $[9,10]$, and their eggs are most frequently observed in examined sites $[1,2$,

Address for correspondence: Laboratory of Parasitoses of Domestic Animals, Institute of Parasitology of the Polish Academy of Sciences, Twarda 51/55, 00-818 Warsaw, Poland

E-mail: gaworj@twarda.pan.pl

Received: 15 January 2014; accepted: 25 June 2014; first published on January 2017
$4,11,12]$. Pet dogs and cats play an important role in the transmission of many helmintic zoonotic agents, with the roundworm Toxocara still persisting in large endemic areas, despite the availability of highly-efficient anthelmintics for dogs and cats [9]. Reported infection rates of T. canis and T. cati in Western Europe vary from 3.5\% - 34\% for T. canis in dogs from different epidemiological environments (pet, shelter, stray, and rural dogs), and from $8 \%-76 \%$ for $T$. cati in cats [13]. Research carried out in Poland showed 34.2\%$72.7 \%$ of young dogs in villages infected with Toxocara, and $18.2 \%-36 \%$ of dogs and cats in towns $[14,15]$. Dogs from rural areas were also found infected with Toxascaris leonina, Ancylostoma/Uncinaria, Trichuris vulpis and tapeworms (Taenia spp., D. caninum) [16]. Carnivores, especially a high population of urban and rural foxes, represent a reservoir of intestinal parasite for humans and the pet dog population. Wild foxes increase environmental contamination and risk of infection with Toxocara canis and tapeworm Echinococcus multilocularis [9]. Examination of faecal samples from foxes in north-western Poland revealed infection with ascarids, whipworms, hookworms and taenids with the prevalence at $18.2 \%-45.5 \%$ [17].

Specific groups of human population have been identified as having a higher risk of acquiring parasitic zoonoses than others. These groups include small children, pregnant women and the immune-compromised. These groups are at a higher risk partly because of behavioural characteristics and partly because of immunological reasons [18]. Young children are mainly at risk of geohelminth infection due to geophagia, onychophagia and poor individual hygiene [11]. 
To evaluate the risk of infection in the rural environment it is important to consider factors such as the soil contamination, age and behaviour of rural inhabitants, pet ownership, and access to feral carnivores. In a study conducted in 2003-2005 in the Mazowieckie Province, a high rate of soil contamination with Toxocara eggs was revealed in yards surrounding houses of children with diagnosed toxocariasis. Despite the diagnosed disease, the children were not adequately supervised by their parents, and no measures taken to avoid further infection [19].

Since there is no current data about the level of geohelminth contamination of households in villages in this region of Poland, and the level of rural inhabitants education on risk factors for zoonotic parasites infection unknown, these issues are addressed in the presented study.

\section{OBJECTIVE}

The objective was to determine the prevalence of geohelminths eggs in the soil samples from rural domiciles, and to assess the awareness of inhabitants about the threat of zoonotic infections on the basis of a questionnaire. In addition, comparison of results of the presented and previous surveys may demonstrate whether implemented promotional campaigns about the prevention of parasitic zoonoses have effected a decrease in their risk in the rural environment.

\section{MATERIALS AND METHOD}

Study area. The survey was carried out in rural households in the Mazowieckie Province of Central Poland between May - September 2012. Several small villages were visited in the same region of the country as in a previous study which aimed to define the risk factors for toxocariasis in children with the diagnosed disease [19]. When passing through villages by car, households were visited in which the presence of children was apparent (toys in the yard, sand pit). Finally, 33 households with 2-3 children present up to 8 years old were chosen for the study. Samples of soil and sand were taken from 55 localities, including 33 backyards, 10 vegetable gardens and 12 sandpits. During the visits, domiciles were inspected and family members were interviewed using a designed questionnaire. The appearance of the farms and sanitation of the domiciles were evaluated (fencing, overall cleanliness, appearance of children's play areas). The questionnaire provided information on the identification of risk factors for helminth infection on the farm level. Questions included details about the number of residents, including children, their age and behaviour conductive to geohelminth infection (geophagia), cases of parasitic diseases in the family (infections with human parasites, toxocariasis, toxoplasmosis, other), number and age of companion animals and their access to a housing area (courtyard, vegetable garden, play area for children, sand pit). Residents were also questioned about the deworming of pets, visits by foreign animals (cats, red foxes and others), sanitation area (cleaning dog/cat excreta), as well as general awareness of the risk of dog and cat zoonotic parasites.

A household consisted of a backyard adjacent to the house, a flower garden in the front and kitchen garden at the back of a house. A typical backyard was fenced-off and had an area of about 400 square meters, it was usually partly grass and partly dense ground. The backyard was used as a children's playground and a resting place for adults. Usually, there was a small sand pit for children in the yard.

Collection of samples. A total of 550 soil and sand samples were collected in 33 examined households from the localities in which children played, i.e. backyards and sandpits, as well as vegetable gardens. At each domicile, 10-30 samples were collected, with 10 samples of approximately 50 grams each taken at each location. Due to the dense ground in the examined yards, samples of soil were taken from the superficial layer of the ground $(0-3 \mathrm{~cm})$. The samples were placed into plastic bags labelled by description and number, according to the relevant questionnaire.

On 3 farms, dog or/and cat excreta were identified (6 from dogs and 2 from cats) at the edge of the yard, and the samples collected to determine and count intestinal helminth eggs.

Parasitological procedures. Extraction of intestinal helminth eggs from soil samples was performed according to the method of Dada [20], with previously described procedures [19], i.e. flotation using combination of Tween pre-treatment and a saturated $\mathrm{ZnSO} 4$ solution (1.52 specific gravity).

No attempts were made to define Toxocara spp. and Trichuris spp. eggs to species level.

\section{RESULTS}

The examination of soil from 33 households in selected villages showed a low level of contamination with the eggs of geohelminths. From the total of 550 examined soil samples, $4(0.7 \%)$ were found to contain helminth eggs, $1-3$ per sample, with an average density of 1.5 and 2.0 Trichuris and Toxocara per sample (Tab. 1). Threadworm and ascarid eggs were found in 3 households (9.1\%). Among the localities examined, contamination was found in 3 from 55 surveyed sites (5.5\%), with positive single samples from 2 yards $(6.1 \%)$ and 1 sandpit (8.3\%).

Table 1. Occurrence of geohelminths' eggs in different settlements in rural households

\begin{tabular}{lccccc}
\hline \multicolumn{5}{c}{33 households in rural areas - positive 3 (9.1\%) } \\
in households in 55 localities - positive 3 (5.5\%)
\end{tabular}

Inspection of the domiciles revealed overall cleanliness, lawns were mowed, the yards well cared for, the children could play on a clean area. The questionnaire provided the following information:

- on 31 farms a dog was present, on 28 farms (84.8\%) dogs were kept chained or fenced-in; the owners of the farms where pets' excreta were found explained that it was exceptional situation because they clean up backyard regularly; 
- none of the examined sandpits $(n=12)$ were covered; sand had not been replaced for at least two years, but only occasionally supplemented.

- the respondents reported no cases of parasitic diseases in their families. Geophagia was not observed in any children; however, behaviour conductive to geohelminth infection, i.e. hand-to-mouth activity was typical for children aged $2-3$ years;

- none of the respondents confirmed the removal of excreta from a zone occupied by dog. All the farm owners confirmed to deworm their dogs minimum once a year, but only $21.2 \%$ of them were able to define the range of effectiveness of the medicine given to a dog (active against roundworms or/and tapeworms);

- a cat was present on 25 farms (75.8\%); however, $63.6 \%$ respondents confirmed that foreign cats had access to their households; none of the respondents confirmed the deworming of their cats; none of the respondents could specify other than the aesthetic aspect of cleaning pets' excreta;

- in dogs/cats, 8 faecal samples from 3 farms, helminth eggs were found in 5 samples from 2 farms, with Trichuris vulpis, Toxocara canis and Ancylostoma/Uncinaria eggs revealed in 4 dogs' and T. cati in one cat faeces. This data was in accordance with the results of soil examination in the backyard on the farm, where Trichuris spp. and Toxocara spp. eggs were found in 1 soil sample. The owner admitted that in previous years, 2 dogs were kept unchained on this farm;

- in the household with a sandpit positive for Toxocara spp., no pet animals were present; however, the owner confirmed that their housing area was visited by cats from neighbouring yards.

\section{DISCUSSION}

A field survey in rural households with consideration of epidemiological factors, such as the contamination of soil, age and behaviour of inhabitants and pet ownership, is valid for evaluating the risk of soil-transmitted helminth infection in humans. The investigated yards in the presented study would be the most likely places of infection for residents, in particular children. The risk, however, was small, since a low level of soil contamination with geohelminth eggs was found in the examined housing areas, with positive single samples from 2 yards and 2 samples from 1 sandpit among 55 sites surveyed. The maximum number of eggs amounted to 5 ova of Toxocara found in samples from a sand pit. In a previous study carried out in the same area of the country [19], a much higher rate of soil contamination with Toxocara was found in rural backyards (29.3\%). This was the result of parents' recklessness and negligence, despite their children being diagnosed previously with toxocariasis. None of these parents had undertaken any measures to avoid further infection in their children, neither by upgrading the sanitation of their housing area (removal of pets' faeces), nor making the area safer by fencing-off the household [19]. In the presented study, a much higher sanitary standard was found on the examined farms. The inspection of domiciles showed that the yards were well maintained, overall cleanliness was observed, which certainly contributed to the significant reduction of contamination of the soil with helminth eggs. The risk of infection for children was not elevated because they were properly supervised, and the mothers followed the rules for keeping the children healthy and clean. However, satisfactory sanitation of the households did not go hand-in-hand with the knowledge and awareness of farm owners about pets' parasites able to infect humans, and the risk of zoonotic diseases. This was evidenced in the example of uncovered sandpits, sand not being replaced sand, and possible visits by feral cats which defecated in the sand pits, representing the most risky place for the infection of small children.

The previous report, which aimed to evaluate the risk of toxocariasis in children in the Łódź Province of Central Poland, Poland revealed a high rate of soil contamination with Toxocara eggs in rural and urban settlements, i.e. $30.4 \%$ and $23.3 \%$, respectively [2]. Similar to the mentioned study [19], in some examined rural domiciles insufficient hygiene and a small degree of owners' negligence was observed [2]. In the study conducted in rural regions of Łódź Province, Ascaris, Toxocara and Trichuris eggs were revealed in $4 \%$ of examined soil samples from gardens, and 60\% from yards, with Toxocara spp. eggs the most often found [5]. The same group of researchers [11] found helminth eggs from 4 genera, namely Toxocara, Trichuris, Ascaris, Uncinaria/Ancylostoma in $9.3 \%$ of samples from public sites in the urban area of Łódź, such as park playgrounds, school sports fields and sandpits in school or kindergarten areas; Toxocara eggs were predominant in the examined sites.

In the presented study, no parasite eggs were found in the soil samples from the 10 vegetable gardens examined. In the previous, Toxocara eggs were also not found in such gardens in rural households; however, in family gardens in urban and suburban environments, the contamination rate was $25 \%$ [19]. In the current study, eggs of Toxocara spp. found, which is an acknowledged zoonotic agent, as well as Trichuris spp., presumably being T. vulpis eggs on examination of dogs' faecal samples. The potential of T. vulpis to infect humans is questionable. Despite cases of visceral larva migrans (VLM) syndrome and patent intestinal infections of Trichuris vulpis in humans reported in medical literature [21, 22], the zoonotic importance of the canine whipworm to develop patent intestinal infection in humans remains controversial. These reports have been questioned because the majority of diagnoses of T. vulpis infection in humans have relied solely on egg measurements, with no thorough morphological or molecular analysis of adult worms [7]. However, taking into account the ability of T. vulpis infective eggs to survive in the environment for many years, human exposure to the parasite in a contaminated environment is remarkably high. It is suggested that T. vulpis should be included among zoonotic pathogens until its potential to infect humans is definitively demonstrated or denied [7].

The results of the presented study are in accordance with the Dubna et al. [1] report from rural areas in the Czech Republic, where the authors found eggs of Toxocara spp. in $5 \%$ of soil samples collected from yards or areas near human habitat in villages. The dogs in rural areas are mostly kept chained or in closed areas around family houses [1], which is also practiced in Poland. The limitation of access for dogs to households is important for avoiding possible contamination of the environment with parasite eggs and, as a consequence, to minimize the risk of infection for inhabitants, in particular when dogs have been rarely or never dewormed. It seems that this manner of keeping dogs in the examined domiciles 
in the presented study significantly contributed to the low contamination of the housing areas. The studies carried out in rural areas in Poland revealed $34.2 \%-72.7 \%$ of guard dogs from households infected with T. canis and T. vulpis [14, 15], as well as $2.9 \%-11 \%$ infected with Toxascaris leonina, Ancylostoma/Uncinaria and tapeworms (Taenia spp., Dipylidium caninum) [16].

In the current study, Toxocara spp. eggs were found in 1 sandpit (8.3\%) among the 12 examined. It can be supposed that the eggs from contaminated pit belonged predominantly to the species T. cati. Cats select sandpits as sand is an ideal substrate for cats to bury their faeces [20]. The presence of feral cats heavily infected with T. cat $i$ is a complicating factor in the prevention of environmental contamination [24]. Urban backyards inhabited by feral cats were found to be highly contaminated (45\%) with Toxocara eggs [1]. The cat population in Poland is estimated at about 6 million, and in rural areas most of them are semi-wild. Cats may maintain a permanent infection level of many parasites. It is therefore important to resolve the situation of feral cats, especially near childrens' play grounds, as the zoonotic potential of T. cati eggs is underestimated compared to T. canis eggs with regard to human toxocariasis [1]. This study shows that the inhabitants of rural domiciles were not aware of the possible risk to their children of infection with zoonotic helminth eggs in the environment; they therefore did not treat sandpits as potentially risky places. Owners of rural domiciles must be aware that irrespective of proper deworming of dogs on a farm, untreated cats which hunt small rodents may be the primary source of soil contamination with ascarid eggs, because small rodents - paratenic hosts of $T$. cat $i$ - have been considered as the most important source of infection for adult cats. In the presented study, T. cati eggs were found in faecal samples collected from the ground on 1 farm.

Similar to previous examinations in Poland and other countries, the presented study confirms pets' ascarids to be the most important parasitic agents in the rural environment. Toxocara spp. eggs were found in 3 samples among 4 positive for geohelminths. The risk of toxocariasis for rural dwellers may be high, as a contamination rate by Toxocara eggs was found in $29.3 \%-73.9 \%$ in rural settlements [2, 3, $4,5,19]$.

This study also showed the low risk of infection for inhabitants in their domiciles and adjacent areas, since only $0.7 \%$ of examined soil samples were found to be contaminated with helminth eggs. This was the result of attention to basic hygiene and cleanliness in the examined domiciles. However, the questionnaire survey revealed insufficient knowledge of the owners of rural households about the existing threats of zoonotic parasites for humans. None of respondents could specify other than the aesthetic aspect of cleaning pets' excreta. The most important epidemiological motivation for dogs' and cats' faeces removal, i.e. to avoid development of parasite eggs to infective stages in the environment to limit human exposure, was not known by the questioned inhabitants. Despite all the farm owners confirming the deworming their dogs, ascarid, whipworm and hookworm eggs were found in faecal samples collected from the ground on 2 farms. Over $90 \%$ of respondents did not consider any intestinal parasite of cats to be hazardous for human health. The presented results indicate that own and also feral cats may be an important reason for contamination with Toxocara cati eggs in rural domiciles.
None of the residents in the current study confirmed cases of parasitic diseases in their family. This could be partly explained their low awareness of zoonotic helminths risk; however, the previous study revealed that even parents whose children were diagnosed with toxocariasis had undertaken no measures to upgrade the sanitation of their housing to avoid further infection [19].

Among the inhabitants of rural areas there are many elderly people who may have a weakened immune system, and may be predisposed to parasitic invasion. Immunocompromised patients need to be aware of possible zoonotic parasites and of all the measures to prevent infections for their pets and for themselves [8].

It is important to take into account that the use of standard centrifuge-flotation techniques for geohelminth eggs recovery is of low sensitivity. The recovery rate of $\mathrm{ZnSO}_{4}$ solution for T. canis eggs is $6-8.8 \%$ [11]. However, in this study and in the previous examinations $[2,19]$, the same technique with the same parasitological procedures were used; therefore, comparison with obtained results seems to be reasonable and appropriate.

\section{CONCLUSIONS}

Data obtained in the presented study show that although the parasitological status of rural households is satisfactory, their inhabitants should be warned and counselled about the risk factors for zoonotic helmintic diseases. In particular, parents should be advised on how to minimize the threat of zoonotic parasites for their children in the rural environment. This study also shows that promotional campaigns on the prevention of parasitic zoonoses implemented during recent years decades have had little effect to increase the awareness of the rural community. However, the risk of zoonotic parasitic diseases is significantly reduced when owners care about the sanitation of their housing, which is evident from the presented study. That Toxocara is the most common zoonotic agent among geohelminths in the rural environment is confirmed by this study and other studies in Poland. Veterinary authorities should inform about the need for the regular deworming of young and adult dogs and cats to decrease the possible soil contamination with pet ascarids. It is worth mentioning that semi-wild cats which are not dewormed may contribute to soil contamination with ascarids within residential areas.

\section{Acknowledgements}

The authors thank the Ministry of Sciences and Higher Education in Warsaw, Poland, for the financial support for this study under Contract No. N N404 044238.

\section{REFERENCES}

1. Dubna S, Langrova I, Jankovska I, Vadlejch J, Pekar S, Napravnik J, Fechtner J. Contamination of soil with Toxocara eggs in urban (Prague) and rural areas in the Czech Republic. Vet Parasitol. 2007; 144: 81-86.

2. Borecka A, Gawor J, Niedworok M, Sordyl B. Occurrence of Toxocara spp. eggs in household environment of children with diagnosed toxocariasis in Łódź voivodeship. Wiad Parazytol. 2010; 56: 141-144. (Abstract in English).

3. Bojar H, Kłapeć T. Contamination of soil with eggs of geohelminths in recreation areas in the Lublin region of Poland. Ann Agric Environ Med. 2012; 19 (2): 267-270. 
4. Kłapeć T, Borecka A. Contamination of vegetables, fruits and soil with geohelmints eggs on organic farms in Poland. Ann Agric Environ Med. 2012; 19(3): 481-485.

5. Błaszkowska J, Kurnatowski P, Damięcka P. Contamination of the soil by eggs of geohelminths in rural areas of Lodz district (Poland). Helminthologia 2011; 48: 67-76.

6. Aydenizöz-Özkayhan M. Soil contamination with ascarid eggs in playgrounds in Kirikkale, Turkey. J Helminthol. 2006; 80: 15-18.

7. Traversa D. Are we paying too much attention to cardiopulmonary nematodes and neglecting old-fashioned worms like Trichuris vulpis? Parasites\&Vectors 2011; 4: 32.

8. Traversa D. Pet roundworms and hookworms: a continuing need for global worming. Parasites\&Vectors 2012; 5: 91.

9. Deplazes P, van Knappen F, Schweiger A, Overgaauw PAM. Role of pet dogs and cats in the transmission of helmintic zoonoses in Europe, with focus on echinococcosis and toxocarosis. Vet Parasitol. 2011; 182: 41-53.

10. Pivetti-Pezzi P. Ocular toxocariasis. Int J Med Sci. 2009; 6: 129-130.

11. Błaszkowska J, Wójcik A, Kurnatowski P, Szwabe K. Geohelminth egg contamination of children's play areas in the city of Lodz (Poland). Vet Parasitol. 2013; 192: 228-233.

12. Gundlach JL, Sadzikowski AB, Tomczuk K. Contamination of selected urban and rural environments with Toxocara eggs. Med Wet. 1996; 52: 395-396

13. Overgauuw PAM, van Knappen F. Veterinary and public health aspects of Toxocara spp. Vet Parasitol. 2013; 193: 398-403.

14. Gawor J, Borecka A. The contamination of the environment with Toxocara eggs in Mazowieckie Voivodship as a risk of toxocarosis in children. Wiad Parazytol. 2004; 50: 237-241.
15. Borecka A. Prevalence of intestinal nematodes of dogs in the Warsaw area, Poland. Helminthologia 2005; 42: 35-39.

16. Tylkowska A, Pilarczyk B, Gregorczyk A, Templin E. Gastrointestinal helminths of dogs in Western Pomerania, Poland. Wiad Parazytol. 2010; 56(3): 269-276.

17. Mizgajska-Wiktor H, Jarosz w. Potential risk of zoonotic infections in recreational areas visited by Sus scrofa and Vulpes vulpes. Case study Wolin Island, Poland. Wiad Parazytol. 2010; 56(3): 243-251.

18. Robertson ID, Irwin PJ, Lymbery AJ, Thompson RCA. The role of companion animals in the emergence of parasitic zoonoses. Int J Parasitol. 2000; 30: 1369-1377.

19. Gawor J, Borecka A, Żarnowska H, Marczyńska M, Dobosz S. Environmental and personal risk factors for toxocariasis in children with diagnosed disease in urban and rural areas of central Poland. Vet Parasitol. 2008; 155: 217-222.

20. Dada BJO. A new technique for the recovery of Toxocara eggs from soil. J Helminthol. 1979; 53: 141-144.

21. Sakano T, Hamamoto K, Kobayashi Y, Sakata Y, Tsuji M, Usui T. Visceral larva migrans caused by Trichuris vulpis. Arch Dis Child. 1980; 55: 631-633.

22. Dunn JJ, Columbus ST, Aldeen WE, Davis M, Carroll KC. Trichuris vulpis recovered from patient with chronic diarrhea and five dogs. J Clin Microbiol. 2002; 40: 2703-2704.

23. Uga S, Minami T, Nagata K. Defecation habits of cats and dogs and contamination by Toxocara eggs in public park sand pits. Am J Trop Med. 1996; 54: 122-126.

24. Overgaauw PAM. Aspects of Toxocara epidemiology: toxocarosis in dogs and cats. Crit Rev Microbiol. 1997; 23: 233-252. 